\title{
Compilação de um corpus anônimo de textos e excertos produzidos no curso Profis
}

\author{
Bianca V. K. Silva*, Inês Signorini.
}

\section{Resumo}

Este trabalho apresenta resultados do trabalho de incorporação de textos e fragmentos de textos produzidos durante disciplina obrigatória do curso ProFIS no primeiro semestre de 2018.

\section{Palavras-chave: \\ Humanidades digitais, linguística de corpus, letramento acadêmico.}

\section{Introdução}

O projeto teve como objetivo fazer a compilação de produções acadêmicas produzidas pelos alunos do ProFIS como atividades da disciplina obrigatória de LA083 - Leitura e Produção de Textos Acadêmicos I, no ano de 2018, para o banco de dados ProCorp, criado em 2017.

O banco de dados ProCorp é o primeiro corpora de aprendiz com produções acadêmicas de universitários ingressantes da Universidade Estadual de Campinas. Trata-se de um banco de dados relevante para o estudo da escrita acadêmica na graduação.

\section{Resultados e Discussão}

O banco do ProCorp recebeu vinte e sete produções acadêmicas compiladas pela, pesquisadora e orientanda de Iniciação Científica (Julia Bahia Adams) no ano de 2017 e cento e vinte seis compilações no ano de 2018. As expectativas para o ano de 2018 eram i) o crescimento do corpus em relação a quantidade e ii) manutenção do desenvolvimento tecnológico do corpus.

O ano de 2018 mostrou-se um ano de produções acadêmicas em um regime excepcional por três fatores: quantidade de produções por 5 turmas (as anteriores foram 4), uma avaliação a mais e a necessidade da adição de mais duas nomenclaturas (RF e $R$ ) em relação aos anos anteriores. A avaliação a mais foi a refacção (RF) de um exercício da Prova 1 (P1). O objetivo da refacção foi dar oportunidade aos os alunos de obterem uma melhor nota. Essa refacção teve de ser incluída na sistematização do corpus com uma nova nomenclatura, de modo a se manter o desenho tecnológico do projeto.

Quanto ao tipo de material inserido no ProCorp, trata-se de exercícios escritos durante as aulas práticas da disciplina, avaliações parciais e exame final. Em função dos objetivos de cada exercício ou avaliação, variou o número de caracteres, palavras e frases referentes a cada documento inserido.

Quanto à preparação dos documentos para inserção no ProCorp, foram incorporados diretamente os documentos já digitados (como por exemplo, as atividades em .doc foram transformadas para .txt) e foram digitalizados os documentos manuscritos.

Gráfico 1. Produções Acadêmicas compiladas dos anos de 2017 a 2018 (até a data de 09/07/2019)

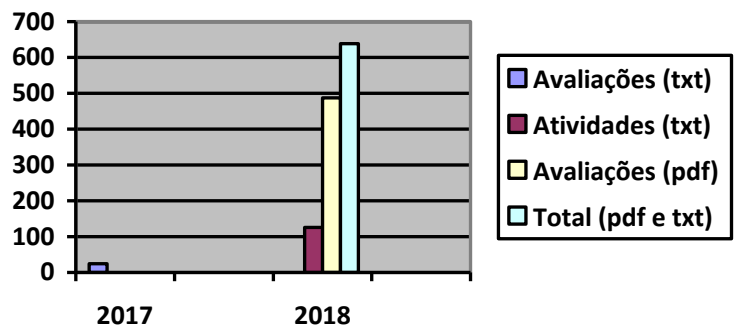

As produções digitalizadas (pdf) totalizam o número de 487, enquanto as produções digitadas (txt) totalizam em 126. Em relação ao total (2017-2018), as produções digitalizadas correspondem a 76,33\% (487 de 638) do total compilado nesses dois anos.

\section{Conclusões}

As produções correspondentes as avaliações I,II,III, refacção, relatório e exame do primeiro semestre de 2018 da disciplina LA083 foram digitalizados (.pdf) e compilados em sua totalidade para o banco ProCorp.

Para 2019, foi orientado que a produção do relatório $(\mathrm{R})$ viesse com uma cópia digital (.pdf ou .txt). A intenção é que esta orientação facilite o trabalho de compilação por reduzir o número de manuscritos a serem digitados.

\section{Agradecimentos}

Agradecimentos ao CNPq pelo auxílio financeiro da concessão da bolsa PIBIC/ Unicamp, cota agosto de 2018 a julho de 2019.

Agradecimento a Inês Signorini pela orientação e apoio durante todo projeto.

ADAMS, J. B. ProCorpus: Compilação de um Banco de Dados de Produções Acadêmicas. Relatório científico da Iniciação Científica 2042/18. Campinas: Fundo de Apoio ao Ensino, à Pesquisa e Extensão, 2018.

GRANGER, S.; LEECH, G. Learner English on computer. [S.1.]: Routledge, 2014 .

NELSON, M. Building a written corpus: What are the basics? In: O'KEEFFE, A.; MCCARTHY, M.(Ed.). The Routledge handbook of corpus linguistics. [S.1.]: Routledge, 2010. p. 81-93.

REPPEN, R. Building a corpus: what are the key considerations? In: O'KEEFFE, A.; MCCARTHY,M. (Ed.). The Routledge handbook of corpus linguistics. [S.1.] Routledge, 2010. p. 59-65.

STUBBS, M. Text and corpus analysis: Computer-assisted studies of language and culture. [S.1.]:Blackwell Oxford, 1996. 